\title{
Bibliometric Analysis of Research Trends on Acupuncture for Neck Pain Treatment Over the Past 20 Years [Response to Letter]
}

\author{
Jaehyeon Park ${ }^{1, *}$ \\ Hyungsuk Kim ${ }^{1,2, *}$ \\ Mi-Yeon Song (1D \\ 'Department of Korean Rehabilitation \\ Medicine, College of Korean Medicine, \\ Kyung Hee University, Seoul, Republic of \\ Korea; ${ }^{2}$ Department of Korean \\ Rehabilitation Medicine, Kyung Hee \\ University Medical Center, Seoul, \\ Republic of Korea
}

*These authors contributed equally to this work
Correspondence: Mi-Yeon Song Department of Korean Rehabilitation Medicine, College of Korean Medicine, Kyung Hee University, 23 Kyungheedaero, Dongdaemun-gu, Seoul, 02447, Republic of Korea

Tel +82 2-440-7|4I

Fax +82 2-958-9104

Email mysong@khu.ac.kr

\section{Dear editor}

We thank the editor-in-chief for giving us an opportunity to respond to the letter from Dong et al regarding our study. We are also thankful to Dong, Qunya and $\mathrm{Wu}$, Wenzhe for their attention to our work and their expert opinion. It is a great honor that our study has been read precisely by other researchers. Herein, we provide our responses to their concerns regarding our work.

First, we searched the Web of Science Core Collection using the terms "acupuncture OR electroacupuncture" AND "cervical pain OR neck pain" on December 4, 2020. This search identified 658 articles at that time. However, on November 2, 2021, a search with the same search terms retrieved in 656 articles. After that, we searched using the suggested search terms, "acupuncture OR electroacupuncture OR electro-acupuncture OR warm needling OR fire needing OR plum blossom needling" AND "cervical pain OR neck pain OR cervicodynia* OR cervicalgia* OR cervicogenic pain OR neckache" with "topic," and the search retrieved 665 articles. Compared to the results of the search with the previous terms on the same day, there were nine additional articles.

None of the nine articles met the inclusion criteria of our study. One study ${ }^{1}$ was not written in English, five studies ${ }^{2-6}$ did not deal with neck pain, two studies ${ }^{7,8}$ did not use acupuncture as an intervention, and one study ${ }^{9}$ was not a human study. Therefore, the suggested search method will not change the results of our study.

However, we agree with the researchers' concise scheme when searching for data. We believe that the more specific the search term, the higher the quality of the data. However, our results were not affected by the search terms. Therefore, we believe that more detailed search terms will be needed in future bibliometric studies to include the maximum number of eligible studies.

Second, as rightly identified by Dong et al, the exact database that we used was the Web of Science Core Collection.

We hope that other researchers will refer to our work and communication for their research using bibliometric analysis.

\section{Disclosure}

The authors declare no conflicts of interest in this communication. 


\section{References}

1. Garrido R. Acupuncture and pain. Rev Med Clin Condes. 2019;30 (6):487-493.

2. Calder KM, Stashuk DW, McLean L. Motor unit potential morphology differences in individuals with non-specific arm pain and lateral epicondylitis. J Neuroeng Rehabil. 2008;5(1):34. doi:10.1186/1743-00035-34

3. France S, Bown J, Nowosilskyj M, Mott M, Rand S, Walters J. Evidence for the use of dry needling and physiotherapy in the management of cervicogenic or tension-type headache: a systematic review. Cephalalgia. 2014;34(12):994-1003. doi:10.1177/0333102414523847

4. Gu T, Lin L, Jiang Y, et al. Acupuncture therapy in treating migraine: results of a magnetic resonance spectroscopy imaging study. $J$ Pain Res. 2018;11:889-900. doi:10.2147/JPR.S162696

5. Haas M, Aickin M, Vavrek D. A preliminary path analysis of expectancy and patient-provider encounter in an open-label randomized controlled trial of spinal manipulation for cervicogenic headache. $J$ Manipulative Physiol Ther. 2010;33(1):5-13. doi:10.1016/j.jmpt.2009.11.007
6. Hanson JL, Goodman EJ. Labor epidural placement in a woman with a cervical spinal cord stimulator. Int J Obstet Anesth. 2006;15 (3):246-249.

7. Serrano NB, Sanchez AS, Lasheras FS, Iglesias-Rodriguez FJ, Valverde GF. Identification of gender differences in the factors influencing shoulders, neck and upper limb MSD by means of multivariate adaptive regression splines (MARS). Appl Ergon. 2020;82:102981. doi:10.1016/j.apergo.2019.102981

8. Huang YX, Zhang JB, Xiong BH, et al. Thunder-fire moxibustion for cervical spondylotic radiculopathy: study protocol for a randomized controlled trial. Trials. 2020;21(1):143. doi:10.1186/s13063-0194012-1

9. Paul C, Suvar T, Goree J, Sanford J, Srinivasan N, Choi H. Comparisons of monopolar lesion volumes with hypertonic saline solution in radiofrequency ablation: a randomized, double-blind, ex vivo study. Pain Phys. 2020;23(2):159-164. doi:10.36076/ppj.2020/ $23 / 159$

Dove Medical Press encourages responsible, free and frank academic debate. The content of the Journal of Pain Research 'letters to the editor' section does not necessarily represent the views of Dove Medical Press, its officers, agents, employees, related entities or the Journal of Pain Research editors. While all reasonable steps have been taken to confirm the content of each letter, Dove Medical Press accepts no liability in respect of the content of any letter, nor is it responsible for the content and accuracy of any letter to the editor.

Journal of Pain Research

\section{Dovepress}

\section{Publish your work in this journal}

The Journal of Pain Research is an international, peer reviewed, open access, online journal that welcomes laboratory and clinical findings in the fields of pain research and the prevention and management of pain. Original research, reviews, symposium reports, hypothesis formation and commentaries are all considered for publication. The manuscript management system is completely online and includes a very quick and fair peer-review system, which is all easy to use. Visit http:// www.dovepress.com/testimonials.php to read real quotes from published authors. 